\title{
A trajetória de um intelectual africano
}

\section{E ntrevista com Toyin F alola*}

E ntrevistadores: $M$ arcel o B ittencourt eR oquinaldo $F$ erréra

1- 0 senhor nasceu na $\mathrm{N}$ igéria e obteve o título de doutor em 1981, na U niversidade de I fé. Pode contar-nos como éser um historiador na $\mathrm{N}$ igéria?

T F - N a N igéria e em quase toda a África, as universidades iniciam suas traj etórias muito bem e adquirem reputação rapidamente, às vezes durante os seus primeiros vinte anos de funcionamento. Para entender minhatrajetória no contexto africano, é preciso considerar a mudança do papel dos professores universitários na sociedade. $\mathrm{N}$ a "época de ouro" da academia, em mead os do século XX, professores universitários eram geralmente muito respeitados. E ram poucos, a nata da elite educada à maneira ocidental. Seus títulos significavam muito: não apenas possuíam experiência e conhecimento, mas sua sabedoria era reverenciada. A dignidade era parte de seu trabal ho. Seu papel, segundo a expectativa de muitos na sociedade, era de orientar o governo, "conversar sinceramente com o poder", mostrando como gerar desenvolvimento econômico e estabilidade política, disseminar conhecimento e formar profissionais. Professores universitários tinham poder, derivado do conhecimento adquirido. A primeira geração de professores universitários não questionou as expectativas da sociedade sobre eles. E stes professores não apenas aproveitavam seu status, mas também vendiam a idéia de que precisavam ser vistos com admiração, dignidade e respeito.

\footnotetext{
* Professor catedrático na U niversity of Texas, Austin, E stados U nidos.

* D eterminação do governo federal americano, que dispõe sobre os centros de pesquisa que dependem de recursos do governo. E ste subsídio governamental viabilizou a emergência de estud os africanos, latinos americanos e também de gênero.
} 
E u não era professor universitário durante esta "época de ouro". I niciei minha carreira quando a academia africana começou a entrar em declínio. Testemunhei a decadência dos professores universitários nos tempos em que era estudante de graduação quando, no outono de 1973, o regime militar do G eneral Yakubu Gowon afirmou, em um pronunciamento na rádio, que todos os professores universitários que desobedecessem às instruções do governo seriam obrigados a deixar suas residências oficiais. Parte das vantagens do trabaIho era acomodação gratuita, uma herança dos tempos coloniais. A torre de marfim foi destruída por um simples pronunciamento de rádio. M uitos se mudaram, outros aceitaram as condições para manter 0 emprego. 0 governo interferiu mais e mais, exercendo seu poder paranomear os membros do conselho, os pró-reitores e os vice-reitores. Centralizava contratações, determinava a cota de cada universidade e a proporção de estudantes a serem admitidos em cada curso. As profissões liberais padeceram, porque o governo acreditava que o país precisava de pessoas graduadas em profissões nas quais poderiam criar seus próprios empregos. A educação na África se tornou um negócio e os professores universitários foram convidados a plantar inhame e quiabo paravender!

Outra grande crise se seguiu: subitamente, nos anos 1970, a N igéria ficou rica com o dinheiro do petróleo. D urante e depois dos anos de boom do petróleo, os que possuíam ligações com os governos estaduais e federal se tornaram prósperos e poderosos da noite para o dia. A sociedade passou a definir o status não em termos de conhecimento e educação nos moldes ocidentais, mas em termos de riqueza e materialismo. A influência da elite ociden- talizada que vinha desde meados do sécuIo XIX, entrou em rápido declínio na década de 1970. Os militares dominaram o poder e perdeu-se muito do respeito pelos professores universitários. A profissão começou a perder seu brilho. Professores universitários naN igéria, e na mai or parte daÁfrica, responderam da mesma maneira: "se você não pode vencê-los, junte-se a eles". Para participar do poder e do enriquecimento muitos entraram para a política ou para o ramo dos negócios. Os professores universitários, a partir de então, precisavam prover a si mesmos, criando oportunidades para dispor de dinheiro e poder economizar para sua aposentadoria. A pesquisa se tornou gradualmente uma ocupação secundária e o compromisso com o ensino declinou.

E u mantive o compromisso com a produção de conhecimento e o ensino. Apesar dos obstáculos, consegui publicar muitos ensaios e livros e contribuí para o treinamento de centenas de estudantes de graduação e pós-graduação. E ncontrei maneiras de conduzir pesquisas que requeriam poucos recursos; elaborei inúmeros projetos com trabal ho de campo; fiz uso extensivo dos recursos do $\mathrm{N}$ ational Archives da N igéria, em I badan, distante menos de duas horas de onde eu vivia; gastei a maior parte do meu salário em pesquisa. As lições que aprendi ainda me são úteis: posso superar desafios e fazer o meu trabalho, como indiquei no meu livro TheP ower of African Cultures que destaca a cultura como resultado de uma ação deliberada.

\section{2- C omo o senhor descreveria a con- tribuição da I badan School of H istory para o desenvolvimento da historio- grafia nigeriana?}


T F - A I badan School (E scola de I badan) se baseia na escrita da história africana de uma perspectiva afrocêntrica, cujos detaIhes são apresentados no meu livro $\mathrm{N}$ ationalism and African Intel lectuals. A melhor maneira de apreciar a contribuição da E scola de I badan para o desenvolvimento da moderna historiografia africana é considerando, de início, a natureza da reflexão sobre a África e o tipo de história africana ensinada antes do surgimento da nova disciplina acadêmica, nos anos 1940. A história africana era ensinada e tratada como a história dos comerciantes, dos missionários e dos exploradores europeus na África. D evido à ausência de documentos escritos os europeus viam a África e seus povos como destituídos de história. As sociedades sem uma tradição de escrita eram vistas como sociedades de povos sem história. 0 degradante e desumano tráfico transatlântico de escravos e as noções não científicas sobre raça e civilização, popularizadas nas palavras de $\mathrm{D}$ avid $\mathrm{H}$ ume, F. G eorg H egel e C harles G . Seligman foram rapidamente incorporadas e orquestradas por numerosos pesquisadores europeus e pelos construtores e administradores do império colonial. $\mathrm{N}$ oções não científicas de história e mudança deram a justificativa intelectual para a colonização e o domínio da África pela E uropa.

A história do surgimento daE scola de I badan está estreitamente relacionada a Kenneth O nwukaD ikeque planejou sua fundação. Significativamente, a nova história africana, da qual $\mathrm{D}$ ike foi pioneiro, foi importante devido à necessidade de demonstrar aos colonial istas que a África tinha uma história antes do domínio europeu. A E scola de I badan forneceu a arma intelectual para a luta nacionalista, já que, como foi dito, parte dajustificativa para a dominação colonial era o fato dos africanos não terem uma história própria. As mudanças começaram nos anos 1950, através de uma reformulação curricular que fez com que a história africana passasse a ser ensinada nas escolase viabilizou a produção de livros que permitiram este ensino e resultaram em novas formas de pesquisa. $\mathrm{N}$ a $\mathrm{N}$ igéria, os cursos ministrados antes da época de D ike contavam a história do I mpério Britânico e das atividades dos europeus na África. Por isto ele enfrentou problemas para desenvolver um novo currículo que atendesse à nova história: a escassez de textos e monografias. Para solucionar este problema $\mathrm{D}$ ike organizou inúmeros congressos, reunindo historiadores, arqueólogos, antropólogos e lingüistas. 0 estudo das populações africanas ganhou uma dimensão multidisciplinar. E le facilitou a fundação do National Archives, em 1953; e criou a $\mathrm{H}$ istorical Society of N igeria, em 1955, fazendo com que a historiografia africana emergisse com toda força. E studantes de pós-graduação foram encorajados a se especializar em diferentes aspectos da história da África pré-colonial e colonial. 0 uso das tradições orais se tornou aceito como método legítimo de reconstrução histórica. A coleção I badan $\mathrm{H}$ istor y Series editada pela $\mathrm{L}$ ongman, foi formada a partir de versões revistas da primeiraleva de teses de doutorado, constituind o uma nova história acadêmica da África. O J ournal of the $\mathrm{H}$ istorical Society of Nigeria e o Tarikh, uma publicação dedicada a diferentes temas, forneceram os instrumentos para a consolidação da nova disciplina. $O$ Groundwork of N igeria $\mathrm{H}$ istory, editado por O baro I kime, foi um projeto encomendado pela $\mathrm{H}$ istorical 
Society of N igeria, visando a elaboração de um compêndio de fácil manuseio e linguagem simples, com a história dos diversos povos da área geográfica da $\mathrm{N}$ igéria, desde antes do estabelecimento do colonialismo até os dias atuais. A dispersão da disciplina aconteceu e ganhou umanova coloração. I gualmente dinâmica era a Ahmadu B ello School of $\mathrm{H}$ istory, basicamente uma escola marxista, liderada por Abdullah Smith. E nquanto o número de universidades crescia nos anos 1960, departamentos de história eram criad os e a propagação da disciplina se acelerava. I badan forneceu mão-de-obraintelectual para novas universidades que surgiram exatamente nos anos 1960. Os principais ensaios produzidos pelaE scolade I badan são agora parte da série que edito, Classic Authors and Texts on Africa.

\section{3- C omo o senhor descreveria sua contribuição pessoal para a historio- grafia nigeriana?}

T F - E m reconhecimento à minha contribuição para a disciplina, meus alunos, amigos e colegas apresentaram três coletâneas de ensaios em minhahomenagem, denominadas TheTransformation of N igeria: E ssays in H onor of Toyin F alola (2002), organizada por Adebayo Oyebade; The $F$ oundations of N igeria: $E$ ssays in $\mathrm{H}$ onor of Toyin F alola (2003), organizada por Adebayo Oyebade; e Precolonial Nigeria: E ssays in H onor of Toyin F alola (2005), organizada por Akim O gundiran. O scapítulosintrodutórios destes três livros enfocam minhas contribuições paraa historiografia nigeriana. D entre elas, encontram-se minhas reflexões sobre a história dos iorubás no século XIX; as melhores análises sobre as reformas econômicas e políticas na
N igéria durante o "colonialismo tardio", juntamente com suas políticas modernas; uma série de livros que investiga a $\mathrm{N}$ igéria, como uma nacionalidade desde os primórdios àatualidade; a anál ise sobre tradições e modernidade; a ligação entre passado e presente, em busca da compreensão do nacional ismo e da construção da nação. A pontam ainda para o sucesso dos meus estudos empíricos sobre a cidadeestado de I badan, em dois livros, que cobrem o período de 1830 a 1939, com atenção especial para a economia política e com a aplicação de vários conceitos e teorias na análise da economia e da política.

Os três livros afirmam que eu toquei em todos os grandes temas, sugeri muitos tópicos que outros desenvolveram e treinei estudantes de pós-graduação. Concordo com eles em todas as questões fundamentais. Através de pesquisas e publicações, expandi a fronteira do conhecimento sobre a $\mathrm{N}$ igéria dos séculos XIX eXX. E m muitos trabal hos pioneiros, produzi um grande corpo de novas pesquisas empíricas que têm sido usadas para cobrir grandes lacunas da literatura, como a compreensão das relações de poder, status, gênero, classe e ideologia entre os iorubás; o desenvol vimento de economias indígenas no contexto de expansão global; a criação de novas culturas à luz da penetração do Cristianismo, do I slamismo e das influências ocidentais; e a possibilidade de aproveitar as idéias africanas para formular modelos importantes não apenas parase entender a África, mas também a própria disciplina histórica. Anal isei a história da N igéria modernadurante o século XX, cobrindo todo o espectro da sociedade. De um lado, importantes questões da história nacional 
foram discutidas em várias publicações sobre política e economia. D e outro, as interações entre as camadas mais baixas da população e a história nacional têm sido igualmente examinadas. E ditando jornais e organizando três col etâneas para diferentes editoras, identifiquei jovens talentos e novas idéias. E staé uma posição de liderança que encoraja e habilita outros acadêmicos a revisarem e publicarem seus trabal hos. Além disto, colaboro para uma dúzia de periódicos, o que me possibilita influenciar positivamente a agenda da academia. De tempos em tempos, organizo workshops, simpósios e congressos para reunir historiadores em debates sobre assuntos diversos. Também contribuí para associações profissionais, inclusive como Secretário Geral da $\mathrm{H}$ istorical Society of $\mathrm{N}$ igeria. F acilitei a circulação de novos conhecimentos nas salas de aula, através da publicação de livros, da formulação de novos cursos e da partici pação na revisão de currícul os. E m vários trabal hos publicados, colaborei com a expansão do conhecimento sobre a África, criando com sucesso el os de ligação entre o grande público e a "torre de marfim". Treinei um grande número de estudantes de graduação e pós-graduação, muitos dos quais se distinguiram em suas variadas trajetórias. U ma reflexão sobre os primeiros anos da minha vida profissional está em minhas memórias, A M outh Sweeter Than Salt.

\section{4- A té os anos 1970, a historiografia sobre o período colonial focaliz ou 0 tema da resistência, em oposição ao colaboracionismo. E mbora esta pers- pectiva deixe de fora inúmeras estra- tégias dos africanos frente ao coloni- alismo, esta dicotomia é ainda usada,}

embora associada a uma nova política, que combina questões étnicas e regionais. $\mathrm{C}$ omo o senhor encara a persistência desta perspectiva?

T F - A base sobre a qual se erigiu esta cultura pós-colonial é frágil, e isto afetou a interpretação do passado col onial. U m trauma acompanhou o encontro colonial, e uma profunda crise se seguiu ao seu colapso. Os africanos tiveram que sair de uma posição de inferioridade cultural e se esforçaram para al cançar uma paridade cultural frente à propagação da cultura ocidental, autodenominada cultura universal, apresentada em oposição às culturas. F oi difícil delinear cada fase deste embate cultural; e a psicologia da opressão dificulta ainda mais a superação dos obstáculos. Acadêmicos e lideranças africanas não compartilhavam a mesma opinião a respeito da solução para a crise pós-colonial na culturae o papel dosafricanos como agentes de transformação do seu continente. A cultura pré-colonial devia ser romantizada e usada na época contemporânea? É possível transcender a cultura colonial? Existem elementos do período colonial que podem ser recuperados? Todas as sugestões revelam o profundo impacto do colonialismo naÁfrica e o legado daquela época, que afeta a historicização dos empreendimentos em termos de resistência e colaboração. A África tem tentado ultrapassar muitos dos problemas relacionados à raça e àcultura, nem sempre com sucesso. 0 fim do domínio colonial reafirmou 0 poder dos negros, mas não necessariamente construções hegemônicas baseadas na idéiada África e dos africanos como agentes no contexto colonial. A luta pela independência derrubou a crença na "inferioridade negra" . Culturas africanas foram 
fortalecidas no pós-independência: o sistema educacional assegurou que a África se tornaria o centro da produção de conhecimento; escritores, artistas, cantores, poetas e outros apresentaram o gênio criativo de seus povos e instituições. Contudo, tem sido difícil manter os ganhos da independência e al gumas crises pós-coloniais têm-se prol ongado mais que as crises coIoniais. N este contexto, dá-se a retomada de vel has idéias, que, mesmo quando desacreditadas, reaparecem como "novas".

\section{5- 0 senhor organizou uma coleção} de livros na U niversidade de $R$ ochester, intitulada A frica and A frican $D$ iaspora, e lançou recentemente uma coletânea de textos sobre a diáspora iorubá, juntamente com $M$ att $C$ hilds. $C$ omo o senhor encara o papel de africanistas não africanos - como Paul L ovejoy, R obin L aw, Kristen $M$ ann e outros - que têm procurado estabelecer uma ponte entre a história da Á frica e os estudos da diáspora africana?

T F - O lugar dos africanistas não africanos no preenchimento das lacunas que separam a história daÁfrica dos estudos sobre a diáspora africana não pode ser superestimado. E ntretanto, alguns deles - como os citados Robin L aw, Paul L ovejoy e $\mathrm{K}$ risten $\mathrm{M}$ ann - desempenharam importante papel no desenvolvimento da historiografia africana. R obin $L$ aw, foi assistente de pesquisa do falecido Professor Saburi Oladeni Biobaku, um dos pais-fundadores da I badan School of $\mathrm{H}$ istory, publicou sua tese de doutorado sobre o antigo império de Oió em 1977; Paul L ovejoy começou sua carreira como historiador econômico, com uma tese sobre o comércio de noz-de-cola, apresentada à U niversidade de Wisconsin-M adison, em 1973. O mesmo se aplica a Kristen $M$ ann, cujo estudo sobre casamento e mulheres em $L$ agos, no século $X I X$, teve significativo impacto na emergência de estudos de gênero. $E$ stes acadêmicos viveram na $\mathrm{N}$ igéria e voltaram para casa, após muitos anos de trabalho de campo na África, para criar novos cursos e áreas de especialização. E les contribuíram muito, abrindo caminho para outros africanistas ocidentais que se interessaram pela África a partir de seus exemplos. A o lado de sua pesquisa sobre os iorubás, R obin $L$ aw publicou estudos sobre a escravidão. Paul L ovejoy, depois de dois anos de pós-doutoramento, atuando como professor na Ahmadu B ello U niversity, em Zaria, tornou-sea mais celebrada autoridade em estudos sobre tráfico de escravos e escravidão na África. E le juntou esforços com outros acadêmicos, como J.D. F age, Philip D. Curtin eJ.E. I nikori para desenvolver e divulgar a história da diáspora africana. Com suas pesquisas estes acadêmicos forneceram uma consistente energia intelectual que trouxe a história da África e do hemisfério ocidental para mais próximo da realidade contemporânea.

\section{6- U m crescente número de africa-} nos está se doutorando e ocupando posições importantes fora da Á frica. 0 senhor considera que eles estão mudando o entendimento do 0 cidente (aqui entendido como $E$ stados $U$ nidos, C anadá eE uropa ocidental) acerca da Á frica em geral e da história africana em particular?

T F - E xistem duas categorias diferentes de acadêmicos africanos no $O$ cidente. $A$ 
primeira é produto da fuga de talentos, resultante da recessão econômica, da procura por melhores condições de trabalho nesses países. A segunda compreende acadêmicos que saíram da África para fazer seus cursos de pós-graduação e por várias razões se recusam a voltar. H áainda um pequeno número de exilados de seus países de origem por razões políticas. A presença de acadêmicos africanos nas universidades do 0 cidente tem contribuído para mudar a percepção que os não-africanos possuem acerca daÁfricae de seus diferentes povos e culturas. De fato, se os africanos não fossem tidos como importante símbolo intelectual e cultural, não seriam contratados como professores. E les apresentam temas relativos à África de uma perspectiva de dentro. E nsinam a história e as culturas nas quais eles cresceram, com um entendimento mais completo, que parte de dentro delas. A maneira pela qual discutem e entendem as culturas e as instituições africanasé incomparável. 0 número crescente de acadêmicos africanos ajuda a preencher a lacuna entre o conhecimento sobre as populações africanas e o processo de transformação destes conhecimentos em produtos acadêmicos prontos para o consumo. E les gozam da reputação de especialistas porque seu conhecimento acadêmico e suas bases culturais se completam, produzindo uma aura de excelência intelectual. Além disto, desempenham papéis importantes na condução dos centros e programas de estudos africanos. 0 presente êxito em termos de números e qualidade das pesquisas levadas a cabo por acadêmi cos africanos e seu papel na mudança da imagem do continente é explicada pela globalização da história africana. Como podemos ver, quanto maior o número de africanistas num departamento de $\mathrm{H}$ istória, maiores serão as chances de se criar um formidável programa de pós-graduação em história e maior é o número de pessoas que provavelmente se tornarão especialistas em África e D iáspora Africana. Acadêmicos africanos, juntamente com seus colegas ocidentais, têm transformado $0 \mathrm{O}$ cidente no melhor lugar para se estudar a história da África. E ste é um êxito inacreditável, embora em detrimento do continente africano. 0 fato de os maiores centros de produção acadêmica sobre a África se localizarem no Ocidente demonstra o sucesso da presença e, mais importante, da produtividade acadêmica tanto de africanos quanto de seus colegas ocidentais.

\section{7- $\mathrm{N}$ a sua opinião, quais são os prin- cipais debates que têm mobilizado os pesquisadores africanos?}

T F - A definição do que vale a pena ser estudado varia de acordo com as preferências intelectuais s os sentimentos de cada pesquisador, e suas convicções pessoais influenciam claramente suas agendas. E sta é a principal razão pela qual a pesquisa histórica no continente tem variado muito de uma geração para outra. Vale lembrar, neste sentido, o provérbio iorubá, "a comida de um homem é o veneno do outro". Além dos interessese das orientações individuais, outro fator preponderante é a disponibilidade das fontes e $a$ acessibilidade às mesmas. 0 ponto a enfatizar é: o número de especial istas trabalhando com o período colonial é maior do que o número de especial istas trabal hando com o período pré-colonial. 
I sso ocorre porque os países africanos possuem arquivos onde se pode encontrar grande quantidade de documentos do período col onial. Por outro lado, por motivos de segurança, expressos em leis, documentos sobre o período pós-independência - que podem ser usados para escrever a história recente - geral mente não estão disponíveis para os pesquisadores. Com isto, em parte devido à ausência de documentos acessíveis, a pesquisa sobre a África pós-independência não tem recebido a atenção adequada. I sto gerou algumas mudanças, envolvendo novas metodologias e fontes e a primazia de fontes arquivísticas tem-se tornado impopular entre al guns pesquisadores. Além disto, existe um outro grupo intelectual que reprova o interesse pela história contemporânea por causa da suafluidez. A dicotomia entre "velha e "nova" história ainda gera grandes debates.

Outro importante fator que influencia o tipo de história produzida pel os historiadores é o que pode ser considerado como corrente intelectual predominante, que é determinado pelas ofertas e demandas do meio acadêmico. 0 ponto a destacar aqui éque houve época em que a história nacional ista foi predominante. As pessoas estavam interessadas em escrever a história de grandes impérios e monarquias existentes antes que a $\mathrm{E}$ uropa estendesse seus tentáculos e sua hegemonia sobre a África. Como mencionado anteriormente, este tipo de história ganhou espaço porque forneceu uma arma intelectual para a descolonização, a política do pós-independência e a construção de identidades sociais. Africanos e não-africanos responderam adequadamente a esta onda e, no início da década de 1980, a historiografia nacional ista se tornou saturada e anacrônica. N ovas formas de pensar acarretam novas disciplinas e novas disciplinas acarretam novas demandas; novas demandas precisam vir acompanhadas de novas ofertas. A demanda é determinada predominantemente por diferentes universidades ou agências de fomento, que desenvolvem seus currículos a seu modo. E sta dinâmicase aplica à emergência de áreas de especialização, como os estudos de gêneros ou a história das mulheres na África. Quando os estudos de gênero emergiram na África, muitos logo começaram a explorar a história das mulheres naÁfrica pré-colonial e colonial. E studos de gênero e história das mulheres ganharam espaço, e muitas pesquisadoras africanas como $\mathrm{N}$ ina $\mathrm{M}$ ba, O niagwu O gbomo, G loria Chukwu, Ifi A madiume e O yeronke O yewumi emergiram com excelentes trabal hos neste campo. Como a fronteira do conhecimento é variável, historiadores oferecem a história requerida, a cada momento. E m parte, isto explica o fenômeno da nova e da vel ha história que formam o fluxo contínuo da produção acadêmica. N ovas teorias e reflexões sempre abrem novos caminhos para a expansão das fronteiras do conhecimento.

Independente do contexto e das mudanças teóricas, questões como subdesenvolvimento econômico e político ainda consumirão muito do nosso tempo enquanto historiadores. "U m homem faminto é um homem furioso", diz um ditado do meu povo. F ace à pobreza, os intelectuais devem se juntar e encontrar soluções para que milhões de homens furiosos pela fome não usem da violência para destruir os intelectuais e suas bibliotecas. 
8- 0 senhor viveu na Inglaterra, no $C$ anadá e, atualmente, vive nos $E$ stados $U$ nidos. $C$ onsiderando sua experiência pessoal, o que o senhor diria sobre multiculturalismo e conflitos culturais?

T F - A globalização possui seus críticos e inimigos. Existem os que lamentam 0 excesso de "estrangeirização" da E uropa; existem sentimentos e movimentos contra os imigrantes nos $E$ stados $U$ nidos. Algumas personal idades importantes da direita americana pretendem preservar os E stados U nid os como um " país cristão", baseado no uso dalínguainglesae em uma "divisão étnica do trabalho", com imigrantes fazend o o que os cidadãos americanos rejeitam. E sta é a contradição da direita, que quer uma América branca (sem o trabal ho barato dos imigrantes), mas que precisa desta mão-de-obra barata; conseqüentemente, a ten dência é importar mão-de-obra estrangeira sem os direitos dos cidadãos ou dos imigrantes tradicionais. Ao invés de abordar problemas individuais, permitam-me enfocar a relação entre nações em um mundo plural em contexto de paz. Para a comunidade global, abandonar a Áfricaé ignorar os danos causados pelo tráfico de escravos, pelo colonialismo, pela guerra fria e por um sistema de trocas internacionais injusto. Pedir reparação para os problemas causados pelo tráfico de escravos e pelo coIonialismo é em parte uma estratégia para gerar um fluxo de riqueza em direção à África na forma de mão-de-obra qualificada, tecnologia, dinheiro, máquinas e idéias. A perícia e o talento dos africanos, independente de onde eles vivem, precisa ser usada para libertar o continente, para derrubar a opressão e a injustiça, para atacar o racismo e para dar início a reformas políticas e econômicas. R eparações precisam incluir cancelamento de dívidas. Para um continente em crise, usar uma grande porcentagem das receitas anuais para o pagamento da dívida externaé perpetuar uma outra forma de escravidão. Os bancos estrangeiros precisam parar de receber dinheiro roubado dos tesouros do continente africano para desenvolver economias ocidentais. Os que vociferam críticas a dirigentes africanos corruptos devem vociferar mais alto condenando seus bancose suas empresas que recebem dinheiro roubado. Os que emprestam dinheiro aos líderes, sabendo que eles são corruptos, que desviam e roubam uma parte dos empréstimos e depositam o dinheiro em contas bancárias de países estrangeiros, não deveriam prejudicar milhões de pessoas pobres e inocentes que não participam destas transações duvidosas. Os que, nos países ocidentais, criticam a imigração, em parte por causa do racismo, equerem parar os fluxos migratórios e limitar as oportunidades para os imigrantes que já estão entre eles, deveriam parar de desperdiçar seu tempo criticando os imigrantes. Ao invés disto, deveriam pressionar seus governantes para combaterem a pobreza na África. As pessoas pobres migram, mesmo correndo grande risco de vida. Todos os " afro-pessimistas" devem lembrar umacoisa: se aÁfrica sobreviveu ao tráfico de escravos e ao sistema colonial, ela também sobreviverá à atual fase de declínio e desordem.

0 multiculturalismo tem vários contextos e dimensões, incluindo o mundo empresarial, a composição do trabal ho, a produção e o consumo cultural, assim como a chegada de uma geração de intelectuais negros que conquistou a educa- 
ção superior depois das lutas pelos direitos civis. Todavia, não devemos confundir o multicultural ismo liberal, que traz consigo um ideal de inclusão, com justiça racial, que exigiria a consideração de fatores variados, incluindo oportunidades iguais de acesso à educação, fundos para desenvolvimento de infra-estrutura, fim da violência racial levada a cabo pelo E stado e participação política substantiva. A recente catástrofe em $\mathrm{N}$ ova O rleans, resultante do furacão Katrina, expôs a dura realidade de raça, classe social e suainterrelação nos E stados U nidos, porquanto os discursos em torno do furacão demonstraram a profunda responsabilidade da hostilidade racial e da agendavenal de alguns segmentos da elite política.

$\mathrm{N}$ a educação superior, testemunhamos as "guerrasculturais" das décadas de 1980 e 1990, que incluíram uma reação contra 0 aumento no número de professores e estudantes negros, assim como a crescente autoridade moral de grupos que articulavam anál ises e estratégias de desenvolvimento educacional em busca dajustiça social. Vale ressal tar que as lutasculturais incluíam ataques contra ações afirmativas e programas de estudos étnicos. D e um lado, podemos ver que o ideal liberal de diversidade é mais aceito na academia, com crescentes esforços nos níveis administrativos, de serviços dirigidos aos estudantes e entre professores paratornar a diversidade um valor vital nas práticas institucionais e de formulação de políticas. D e outro lado, a educação superior é a chave para um ajuste estrutural, o que significa que as regras de financiamento estão sendo redefinidas, 0 acesso às instituições de elite está sendo restrito e a instituição da estabilidade para professores universitários (denominada tenure) está sendo atacada.

Ademais, a realidade presente e as perspectivas futuras da acad emia devem ser entendidas no contexto da expansão do neo-imperialismo. A ligação entre as populações negras dos E stados U nidos, despossuídas de seus direitos políticos, e as vítimas das aventuras americanas no exterior podem não ser facilmente identificáveis em instituições de elite como universidades, mas esta ligação é inegável e determinará o acesso, o suporte, a promoção, assim como as agendas de ensino e pesquisa. A tentativa do governo americano de intervir na autonomia das áreas de estudos referidas no TitleVI * representa uma agressão direta às lutas e às conquistas dos movimentos em prol da diversidade cultural. D e fato, a complexa relação entre educação superior, mercado de trabal ho e lideranças políticas e sociais sugere que a luta pela justiça racial e pela equidade cultural está longe do fim; nós não podemos ter uma posição otimista e acreditar que as coisas estão melhorando. 